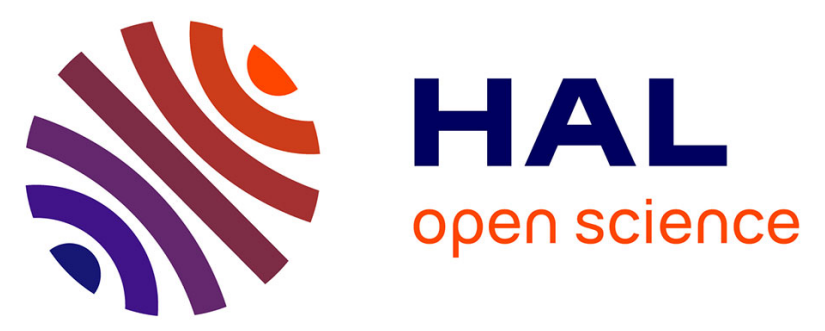

\title{
Two new in-plane torsion tests for the investigation of self-heating under pure shear cyclic loading
}

Julien Louge, Rémi Munier, Cédric Doudard, Sylvain Calloch, Bastien Weber

\section{To cite this version:}

Julien Louge, Rémi Munier, Cédric Doudard, Sylvain Calloch, Bastien Weber. Two new in-plane torsion tests for the investigation of self-heating under pure shear cyclic loading. International Journal of Fatigue, 2021, 149, pp.106256. 10.1016/j.ijfatigue.2021.106256 . hal-03254750

\section{HAL Id: hal-03254750 \\ https://hal-ensta-bretagne.archives-ouvertes.fr/hal-03254750}

Submitted on 23 Jun 2021

HAL is a multi-disciplinary open access archive for the deposit and dissemination of scientific research documents, whether they are published or not. The documents may come from teaching and research institutions in France or abroad, or from public or private research centers.
L'archive ouverte pluridisciplinaire HAL, est destinée au dépôt et à la diffusion de documents scientifiques de niveau recherche, publiés ou non, émanant des établissements d'enseignement et de recherche français ou étrangers, des laboratoires publics ou privés. 


\title{
Two new in-plane torsion tests for the investigation of self-heating under pure shear cyclic loading
}

\author{
Julien Louge ${ }^{\mathrm{a}, \mathrm{b}, *}$, Rémi MunieR ${ }^{\mathrm{b}}$, Cédric DoudarD $^{\mathrm{a}}$, Sylvain $\mathrm{CAlloch}^{\mathrm{a}}$, \\ Bastien WEBER ${ }^{\mathrm{b}}$ \\ ${ }^{a}$ École Nationale Supérieure de Techniques Avancées Bretagne - Institut de Recherche \\ Dupuy de Lôme (IRDL), UMR CNRS 6027 - 2, rue Franois Verny, F-29806 Brest Cedex 9, \\ France \\ ${ }^{b}$ ArcelorMittal Global RED - BP 30320, F-57283 Maizières-lès-Metz Cedex, France
}

\begin{abstract}
The fatigue limit under a pure shear loading is very complex to determine for thin sheet materials. In this paper, two new specimen geometries are proposed to assess the fatigue limit under this condition using self-heating measurements for isotropic material. Both new geometries are disc-shaped with particular designs to promote a homogeneous stress field. Strain gauge measurements confirmed that the applied strain fields correspond to a pure shear condition. The thermal fields were imaged by an infrared camera, demonstrating the validity of using a 0D thermal approach. In this way, fatigue limits under pure shear loading could be determined.
\end{abstract}

Keywords: shear stress, high cycle fatigue, self-heating measurements, sheet metal

\section{Introduction}

In multiaxial fatigue, the parameters typically required for fatigue criteria are fatigue limits under cyclic tension as well as fatigue limits under pure shear loading, such as the Crossland criterion [6]. However, fatigue limits under pure shear loading are difficult to obtain in the case of thin steel sheets (i.e. less

\footnotetext{
* Corresponding author at:

Email address: julien.louge@ensta-bretagne.org (Julien LoUGE)
} 
than 5mm thickness) 3, 41. Cyclic shear tests are usually performed on cylindrical specimens that cannot be machined from thin steel sheets, or on tubular specimens. Concerning the latter geometry, specimens could be fabricated by sheet rolling and welding. In that case, hardening would be induced by the rolling step and the welding join would make the material heterogeneous [7, 15]. Consequently, the material could not be characterized in its as-delivered state. Therefore, the common approach to assess parameters for fatigue criteria considers fatigue limits under cyclic tension for two different load ratios (usually $R=-1$ and $R=0.1$ ) but this reduces the accuracy of the criteria [15]. In order to overcome this limitation, a new experimental test is proposed in this article.

The aim of this study is to design, perform and validate a new testing device for high cycle fatigue characterization under pure shear cyclic loading of flat steel samples using self-heating measurements under cyclic loading. These measurements have been studied for several years in order to reduce the time dedicated to the estimation of high cycle fatigue properties $44,5,8,13,18,20,26,32,33,38$. The principle is to apply a succession of series of cyclic loading with a constant stress amplitude, which increases for each series [7, 32]. The temperature evolution is recorded during each loading sequence providing information about the intrinsic dissipation of the material. Then, a probabilistic two-scale model is used to link this intrinsic dissipation evolution under cyclic loading to the microplasticity evolution inside the material, which is the mechanical mechanism responsible for failure by fatigue [21, 22]. It is assumed that the intrinsic dissipation is only due to the microplasticity mechanism [9, 31, 33]. Hence, it is possible to assess the high cyclic fatigue properties for a metallic material in few hours by only considering one sample.

In this study, the selected specimens are deigned to meet two specific requirements: firstly the geometry must be compatible with cyclic loading and secondly with a 0D thermal approach for self-heating measurements [24, 31. With a 0D thermal approach, the stress state in the useful zone must tend toward a homogeneous shear stress field. This kind of approach is the easiest way to use self-heating measurements and does not require specific equipment 
such as an infrared camera [9, 14, 32. Thus, the main advantage of the two new specimens proposed here is that the fatigue properties under cyclic shear loading can be assessed easily in the as-delivered state.

This paper begins with a bibliographic review of existing shear loading fatigue tests for flat samples, highlighting the need for a more efficient test using self-heating measurements under cyclic loading. Then, the design of two new geometries is proposed as well as the testing device. Finally, the self-heating measurements for both geometries are plotted. To conclude, the fatigue limit under shear conditions is assessed, making the determination of a multiaxial fatigue criterion possible and more accurate than with the common approach. Since classical fatigue tests under shear conditions are difficult to perform on thin steel sheets without modifying the state of the material, the comparison between the results from the two new specimens proposed and a regular fatigue campaign is not possible.

\section{Current state of shear testing for sheet materials}

A literature review was conducted in order to make an inventory of primarily used shear tests [3, 41] grouped in two categories : shear tests for characterization of plastic hardening of sheets and shear tests for characterization of fatigue properties of sheets. Although only four tests are presented for the first category, various approaches have been proposed [16, 19, 29, 30, 34, 36, 37] having the same limitation regarding cyclic loading.

\subsection{Shear tests for characterization of plastic hardening of sheets}

The first test presented is the simple shear test, originally proposed by $\mathrm{K}$. Miyauchi 28. The sample is rectangular-shaped with three clamping areas, two fixed at both sides and one mobile at the center. This is why the sample has two symmetrical useful zones. The force is applied at the middle clamp and the shear stress is produced by the parallel displacement of the middle clamp relative to the fixed ones, as shown in figure 1. Due to the symmetry, the 
shear forces are balanced in the two useful zones. This test is very efficient for mechanical characterization and for identification of behavior laws [2, 17, 23, 35]. The theoretical shear stress $\tau_{\text {theo }}$ in each useful zone is determined by

$$
2 \times \tau_{\text {theo }}=\frac{F}{L . e}
$$

where $F$ is the applied force at the middle clamp, $L$ and $e$ are respectively the height and the thickness of the specimen. To observe the stress field induced by a tensile loading, a finite element simulation was conducted in Abaqus/Standard considering only one useful zone. The value of the force $F$ is arbitrarily chosen at $40 \mathrm{kN}$ to obtain a theoretical elastic shear stress at the center of the useful zones of 100MPa. The numerical results, in figure 2, show that the stress field is homogeneous except on the edges and the mean stress is practically equal to the theoretical value. This test has many advantages such as using a simple specimen with no complex machining which could lead to stress concentrations. A large deformation can be applied and the loading can be reversed. Nevertheless, precautions have to be taken to avoid any deformation in the area of the sample under the clamps, which may occur due to the torque created by the tensile force [2]. This phenomenon could also disturb the thermal measurements.

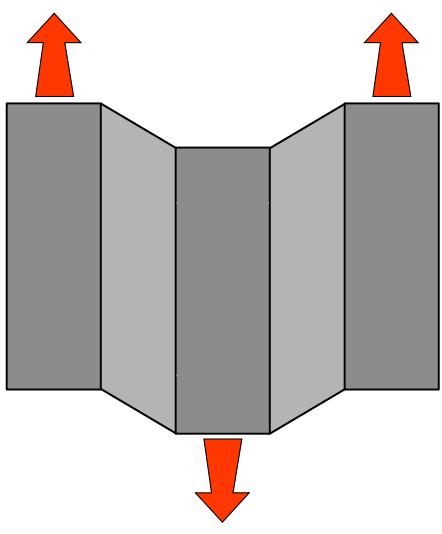

(a) Test principle

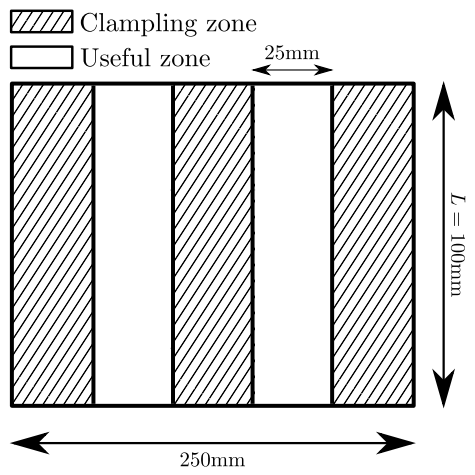

(b) Sketch

Figure 1: Simple shear test 
Moreover, under compressive loading, buckling effect can occur. Consequently, cyclic loading cannot easily be applied.

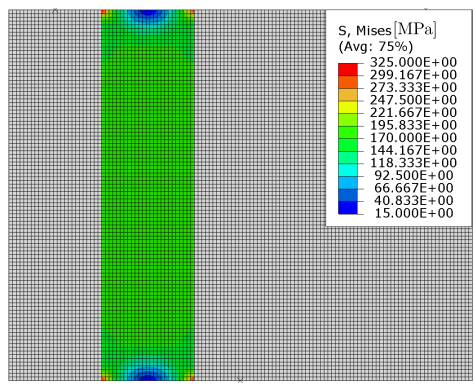

(a) von Mises stress

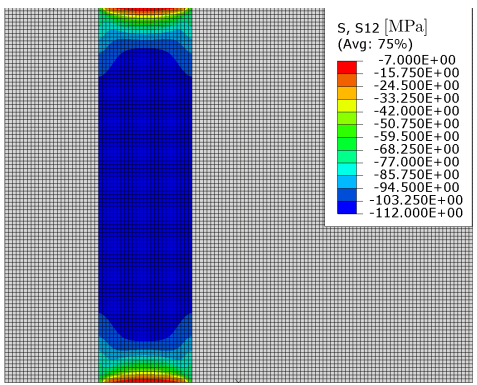

(b) Shear stress

Figure 2: Finite element analysis results for the simple shear test

The second test presented was developed in the frame of the ASTM (American Society for Testing and Materials). They developed their proper shear test to study aluminium sheet behavior, related to the ASTM B831 standard [1, considering a specimen with a localized useful zone, shown in figure 3(a) This test is more efficient than the simple shear test 35] with the advantage of analysing the in-plane plastic anisotropy of metals. However, an unwanted rotating movement is created at the center of the specimen due to its geometry. To overcome this problem, Merklein and Biasutti proposed another geometry [27, shown in figure [3(b)] In addition, this improved geometry makes loading reversal possible and cyclic loading can be applied. For thin sheets, particular attention has to be drawn to the buckling effect under compressive loading [39]. The theoretical shear stress in the useful zone for both geometries is given by

$$
\tau_{\text {theo }}=\frac{F}{L . e}
$$

where $F$ is the applied force, $L$ the length of the useful zone and $e$ the thickness of the sample. The stress fields in the useful zone are shown respectively in figures $4(\mathrm{a})$ and $4(\mathrm{~b})$ for the B831 Standard and in figures 4 (c) and $4(\mathrm{~d})$ for the improved geometry. The applied force is $940 \mathrm{~N}$ in order to obtain a theoretical 
shear stress of 100MPa. The shear stress field is almost homogeneous in both useful zones with small areas of stress concentration at the edges. The numerical value is near to the theoretical one.

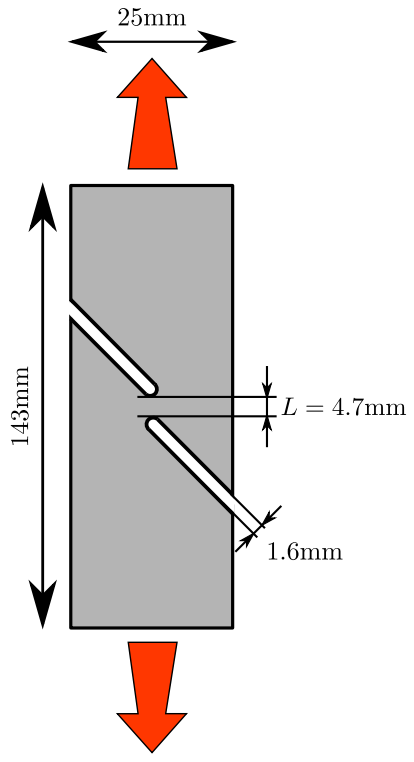

(a) B831 Standard

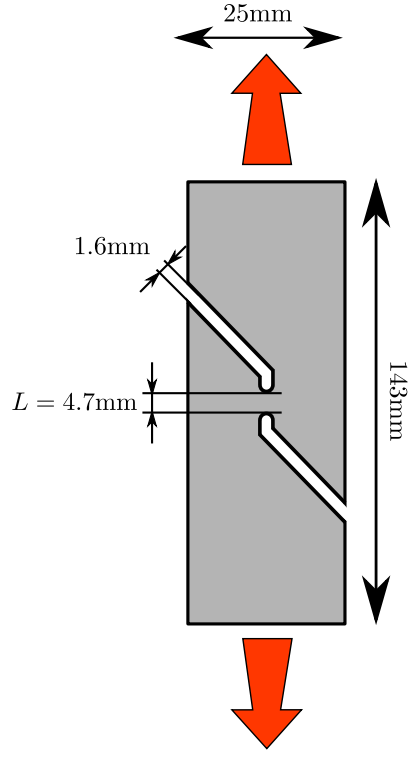

(b) Improvment

Figure 3: ASTM shear test

Other tests propose to generate shear stress via a rotating movement instead of a translational movement. The first and simplest of these is the in-plane shear test considering a disc specimen proposed by Marciniak to study cyclic hardening of copper [25]. The outer zone of the disc (the largest disc radius) is fixed and the rotating movement is transmitted through the inner zone (the central zone of the disc). The relative rotational movement between the outer and inner zones creates the shear stress in the useful zone, shown in figure 5. The theoretical shear stress depends on the radius and is given by

$$
\tau_{\text {theo }}(r)=\frac{C}{2 \pi \cdot e \cdot r^{2}}
$$

where $C$ represents the torque, $e$ and $r$ are respectively the thickness and the 


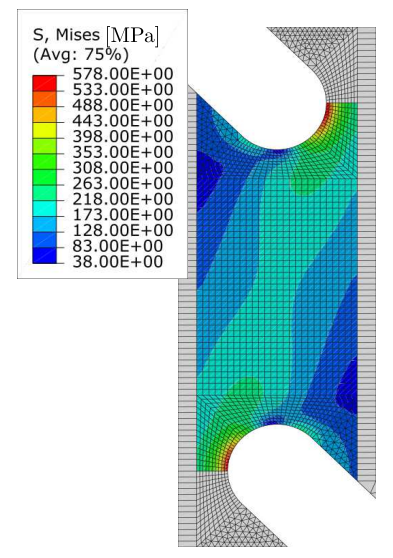

(a) B831 - VMS

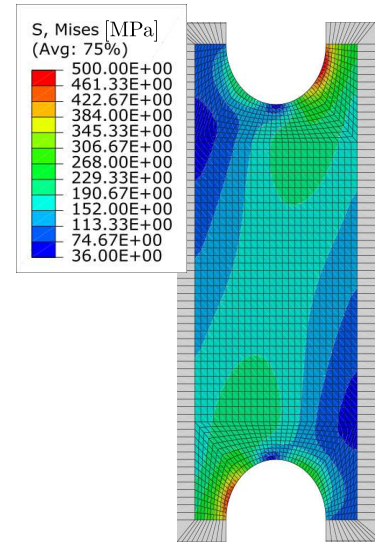

(c) Improved - VMS

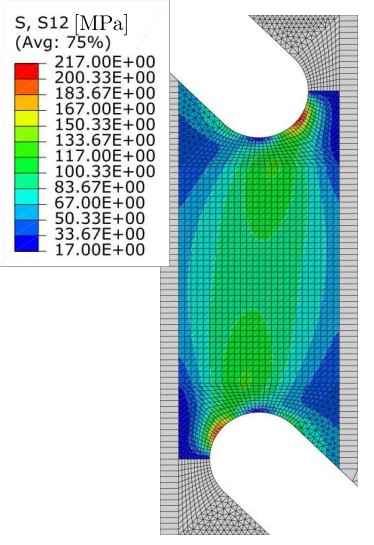

(b) B831 - SS

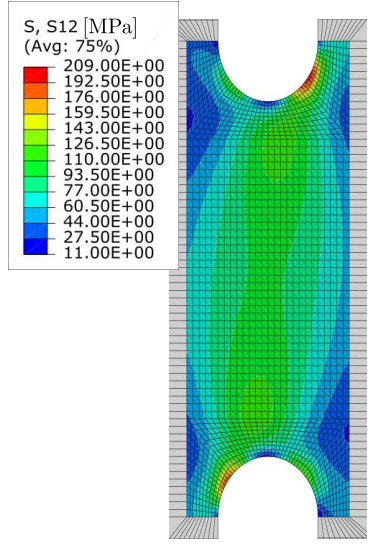

(d) Improved - SS

Figure 4: Finite element analysis results for the ASTM B831 Standard and the improved geometry (VMS = von Mises stress, $\mathrm{SS}=$ shear stress)

radius of the sample. The mean shear stress value in the useful zone is given by

$$
\begin{aligned}
\tau_{\text {theo }}^{\text {mean }} & =\left(\frac{1}{R_{\max }-R_{\min }}\right) \int_{R_{\min }}^{R_{\max }} \frac{C}{2 \pi \cdot e \cdot r^{2}} d r \\
& =\frac{C}{2 \pi \cdot e\left(R_{\max }-R_{\min }\right)}\left(\frac{1}{R_{\min }}-\frac{1}{R_{\max }}\right)
\end{aligned}
$$

where $R_{\min }$ and $R_{\max }$ are the inner and outer radius. The torque is set to $1005 \mathrm{Nm}$ to obtain a mean shear stress at 100MPa. The main drawback of this 
solution is that the stress field is not homogeneous in the useful zone, illustrated in figure 6, making the self-heating measurements analysis using a $0 \mathrm{D}$ thermal approach more difficult. In addition, the maximal torque needed requires a high load capacity $(1005 \mathrm{Nm}$ to obtain a mean shear stress at $100 \mathrm{MPa})$.

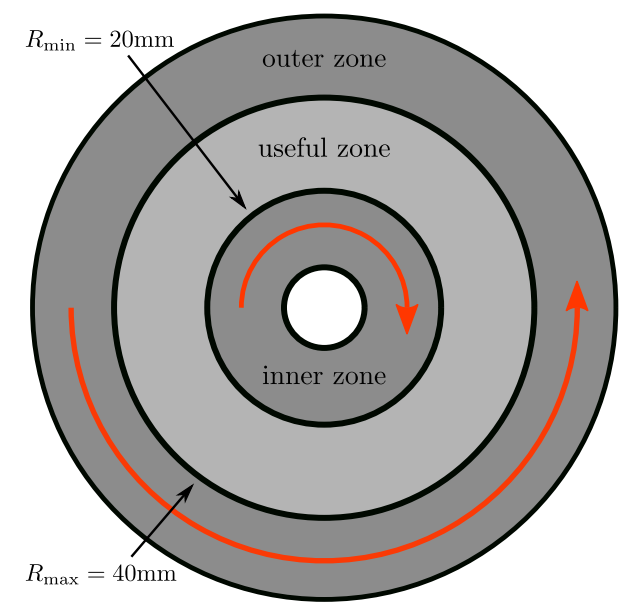

Figure 5: In-plane shear test

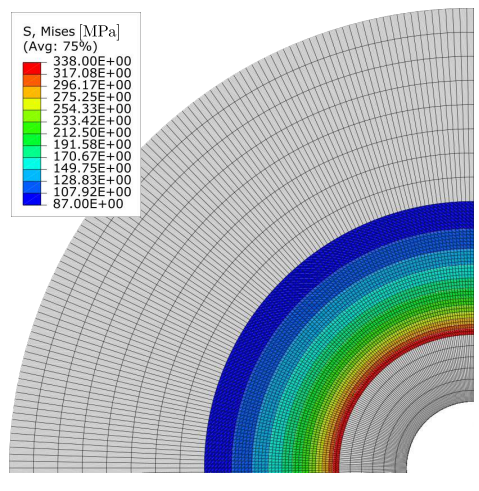

(a) von Mises stress

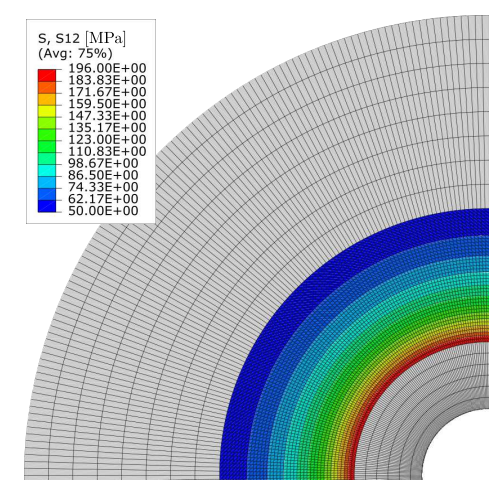

(b) Shear stress

Figure 6: Finite element analysis results for the in-plane shear test

In order to study the anisotropy effect on material properties under shear loading on rolled steel, a modification of the in-plane shear test was developed 
by Brosius [3] named TwinBridge. Slots are cut from a disc specimen to obtain two symmetrical useful zones, as shown in figure 7. The anisotropy effect can be analyzed by removing material at different angles with respect to the rolling directions. The theoretical shear stress is

$$
\tau_{\text {theo }}=\frac{C}{2 \cdot e \cdot \Delta \theta \cdot R_{\mathrm{m}}^{2}}
$$

computed at the median line $R_{\mathrm{m}}=21.5 \mathrm{~mm}$ of the useful zone and with $\Delta \theta=$ $20^{\circ}$. The torque is set at $65 \mathrm{Nm}$ to get a theoretical shear stress at $100 \mathrm{MPa}$. The main advantage is that the maximal torque needed is much lower than the classical in-plane shear test using a full disc because the total useful zone area is greatly reduced. However, some stress concentrations occurred on the edges, shown in figure 8, which could disturb the thermal field in the context of selfheating test under cyclic loading. In addition, the useful areas are too small (2mm width and $\Delta \theta \times R_{\mathrm{m}} \approx 7.5 \mathrm{~mm}$ length) to correctly measure the thermal evolution and to use a 0D thermal approach. Other authors have been working on this kind of specimen [40] but the useful zone width is also too small.

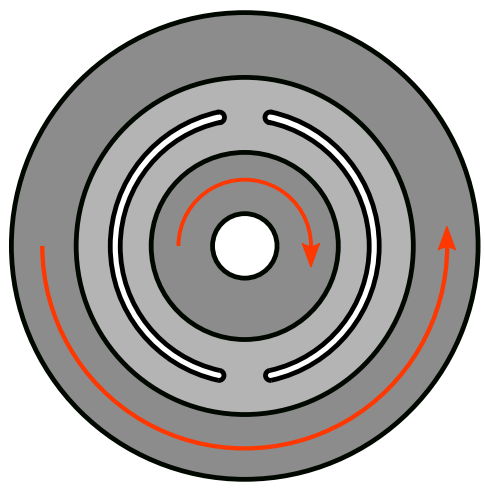

(a) Test principle

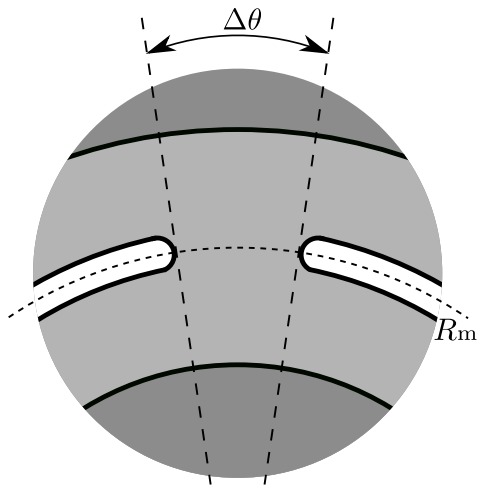

(b) Sketch

Figure 7: TwinBridge shear test $\left(\Delta \theta=20^{\circ}\right.$ and $\left.R_{\mathrm{m}}=21.5 \mathrm{~mm}\right)$ 


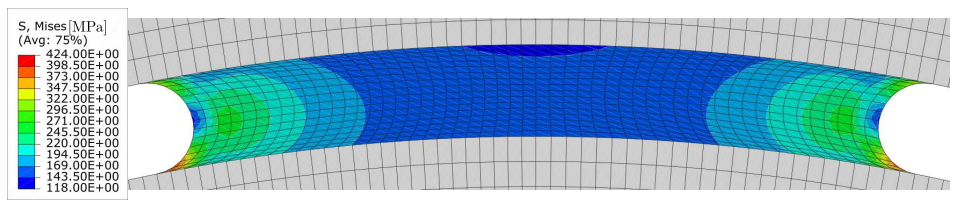

(a) von Mises stress

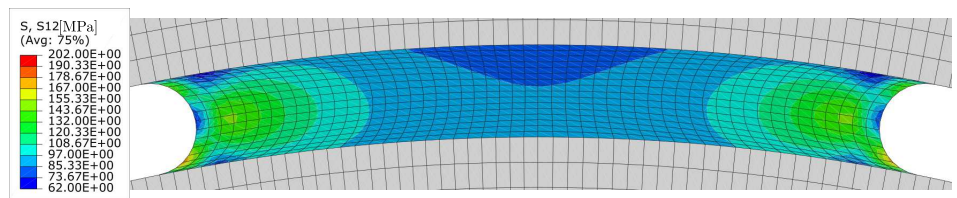

(b) Shear stress

Figure 8: Finite element analysis results for the TwinBridge shear test

\subsection{Shear tests for characterization of fatigue properties of sheets}

For fatigue characterization of flat steel, ArcelorMittal has developed a fatigue shear test named SAMSHEAR [15]. The sample geometry, shown in figure 9, is close to the simple shear test but with two section reductions. The first one is in the width (machining of two notches with radii of $20 \mathrm{~mm}$ ) to avoid

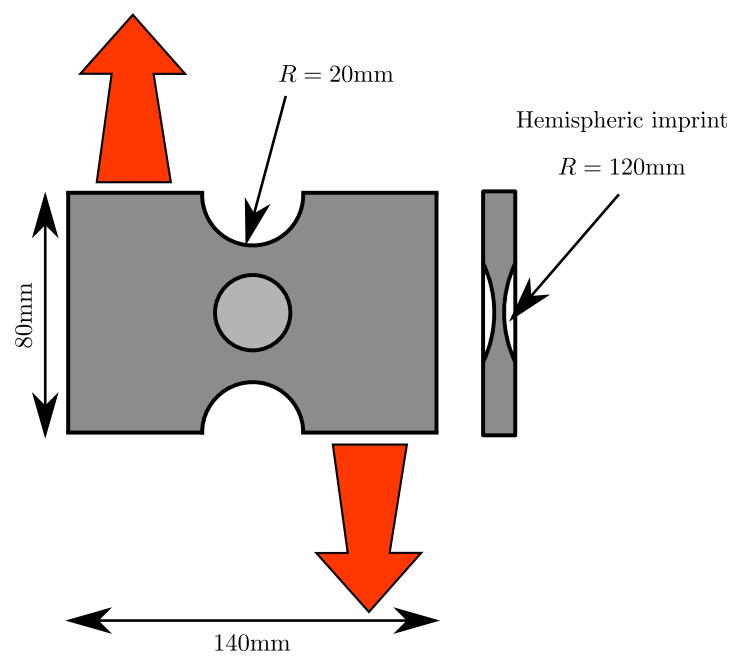

Figure 9: SAMSHEAR test 
problems occurring with the simple shear test, i.e. slip movements under the clamps, and also to obtain a maximum stress in the center of the sample. The original version used a constant thickness over the whole specimen. However, the hydrostatic pressure was at its maximum at both external radii. It was also found that there are stress concentrations in sense of von Mises at the same location, with a magnitude lower than at the center but still significant. The combination of those two phenomena often led to premature failures and crack initiations at one of external radii instead of at the center of the sample. In order to avoid this problem, a hemispherical electro-erosion was performed with up to $50 \%$ thinning to concentrate the maximal stress at the center of the useful zone. The sample is clamped on two areas, one to the upper grip of the machine which is fixed and the other to the lower grip which is mobile. This design, which is possible because of a complex machining, requires finite element analyses in order to assess the pure and maximal shear stress states at the center of the sample. There is no analytical solution to link the force applied to the shear stress induced by this force. For the numerical analysis, shown in figure 10, the applied force is $8 \mathrm{kN}$ which would have led to a theoretical shear stress of $100 \mathrm{MPa}$ if the thickness was constant. Unfortunately, the coupling is-

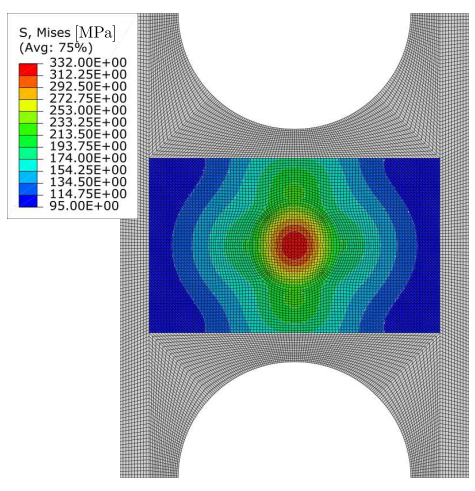

(a) von Mises stress

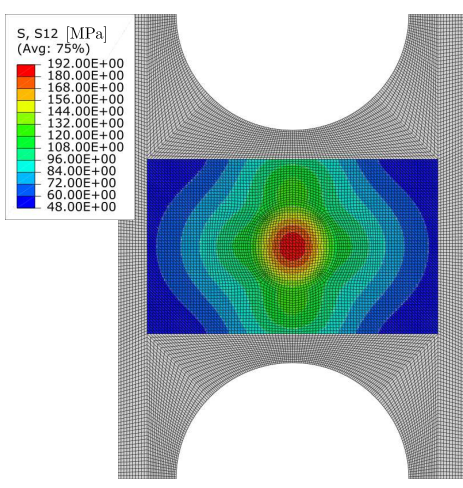

(b) Shear stress

Figure 10: Finite element analysis results for the SAMSHEAR test 
sue between the shear stress and the hydrostatic pressure is only reduced. Crack initiations often occurred at one of external radii so some tests are not usable. In addition, with this geometry, the shear stress is concentrated in one point at the center of the sample and the stress field is not homogeneous in the useful zone. Consequently, a 0D thermal approach cannot be used from self-heating measurements.

\subsection{Summary}

None of the tests presented above can meet all the requirements for the characterization of shear fatigue properties of steel sheets using self-heating measurements under cyclic loading. Most of them were developed for plastic hardening characterization under quasi-static loading. It would be very difficult to apply a cyclic loading and maintain a pure shear stress field. The SAMSHEAR test could be used because it was developed for fatigue tests. Unfortunately, due to the coupling between the shear stress and the hydrostatic pressure and, more importantly, because the stress field is non-homogeneous, this test cannot be used. The two interesting geometries are the in-plane shear and the Twin-

Bridge tests. Cyclic loading can be applied on both specimens. However, to obtain a homogeneous shear stress field, the shape has to be redesigned. This will be presented in the next section.

\section{Design of in-plane torsion tests under cyclic loading}

In this section, two new geometries of specimen are proposed for shear fatigue properties characterization from self-heating measurements under cyclic loading. Both geometries were designed from a disc specimen, illustrated in figure 11. In this case, it was shown in equation 3 that the shear stress is not homogeneous along the radius in the useful zone. In order to obtain a homogeneous thermal field, the stress field must tend toward a homogeneous shear stress field. To this end, the section of the useful zone has to evolve as a function of $1 / r$. 


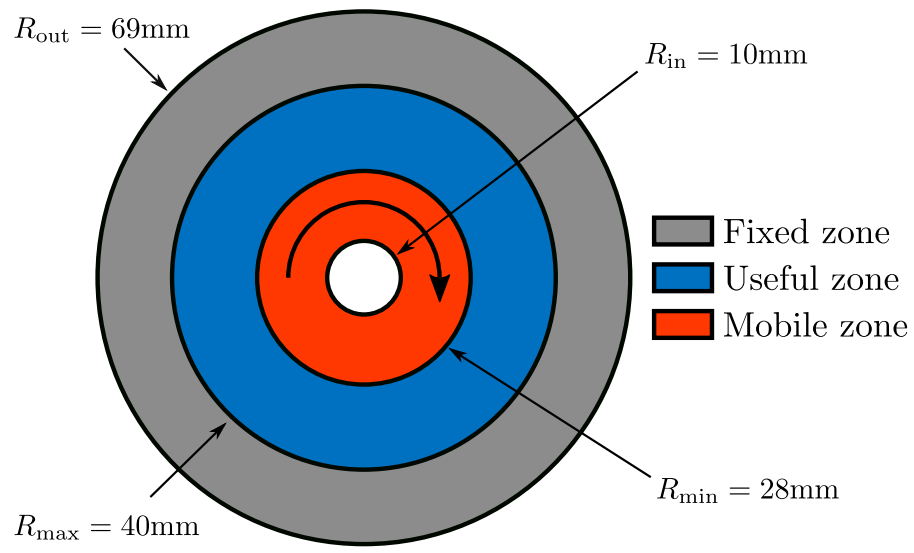

Figure 11: Disc specimen settings (initial thickness $e_{0}=2 \mathrm{~mm}$ )

\subsection{First proposition : a pure shear disc specimen}

The first proposed geometry presents a variable thickness as a function of the radial position in the useful zone, illustrated in figure 12 The section is defined by

$$
S(r)=2 \pi \cdot r \cdot e(r)
$$

with $e(r)$ the thickness evolution to be determined. To obtain a homogeneous stress field, i.e. a constant shear stress, the thickness has to evolve as a function of $1 / r^{2}$, such as

$$
\begin{array}{rll}
\forall r, \quad \tau(r)=\frac{C}{2 \pi \cdot r^{2} \cdot e(r)}=c s t & \Rightarrow & r^{2} \cdot e(r)=c s t=a \\
& \Rightarrow & e(r)=\frac{a}{r^{2}}
\end{array}
$$

with $a$ a constant parameter to be determined from the boundary conditions. At the minimum radius $R_{\min }$ the thickness is equivalent to the nominal $e(r=$ $\left.R_{\min }\right)=e_{0}$. To satisfy this condition, the $a$ parameter has to be equal to $R_{\min }^{2} \cdot e_{0}$, which leads to

$$
e(r)=\frac{R_{\min }^{2} \cdot e_{0}}{r^{2}}
$$

with $R_{\min }=28 \mathrm{~mm}$. This value, defining the clamping area of the sample, is determined from the second geometry in order to use the same testing device. 
For this first geometry, the stress field will always be homogeneous regardless the value of $R_{\min }$. The higher the value of $R_{\min }$, the more important the clamping area will be. Consequently, the greater the transmissible torque. A cross sectional view of this final geometry is provided in figure 13 .

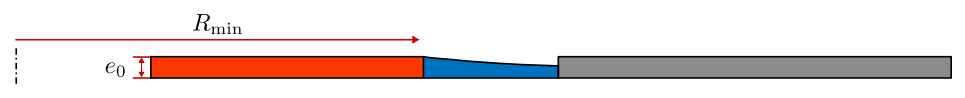

Figure 12: Settings geometry of the pure shear disc specimen

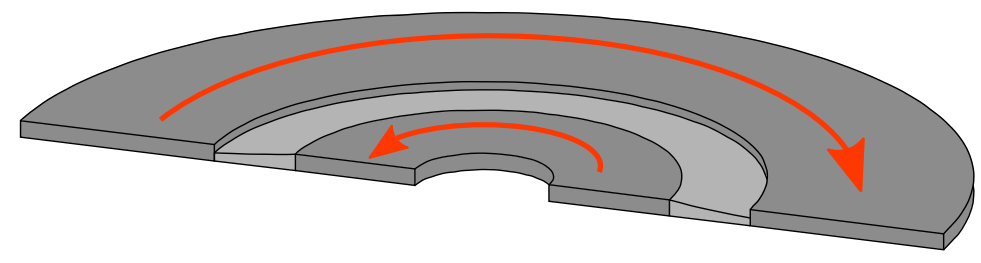

Figure 13: Cross sectional view of the pure shear disc specimen

The numerical results are reported in figure 14 and confirm the stress field homogeneity in the useful zone as expected. This solution is very close to the theoretical one, nevertheless some care must be taken during the machining operation to ensure the required section. This solution seems to meet all the requirements, which are the ability to apply a cyclic loading and a homogeneous shear stress field in the useful zone. But it has one significant inconvenience regarding the torque levels. In order to reach the higher shear stresses for self-heating curves, the matching torque could be greater than the maximal transmissible torque by the testing device, which is limited by the clamping area and the clamp force.

\subsection{Second proposition : an openshaped shear disc specimen}

The second geometry was designed with the aim of reducing the maximal torque from the complete disc specimen shown in figure 11. To this end, two shaped slots were cut, called openshape, to obtain two symmetrical useful zones, 


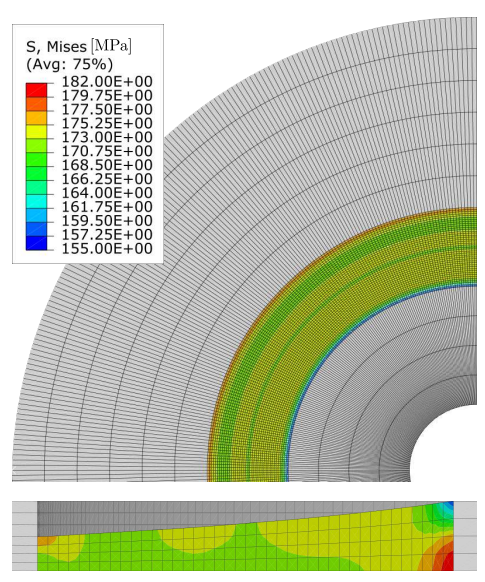

(a) von Mises stress

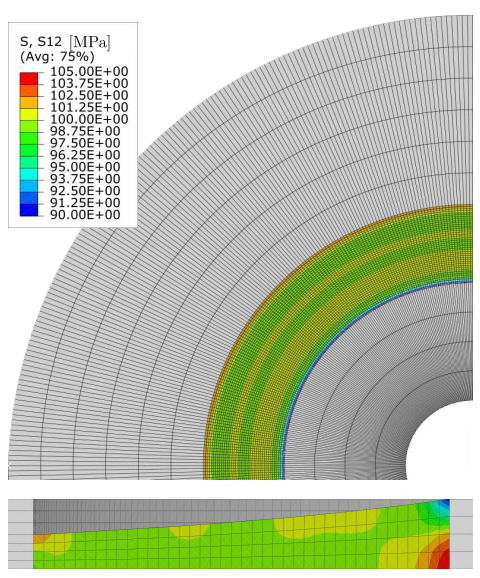

(b) Shear stress

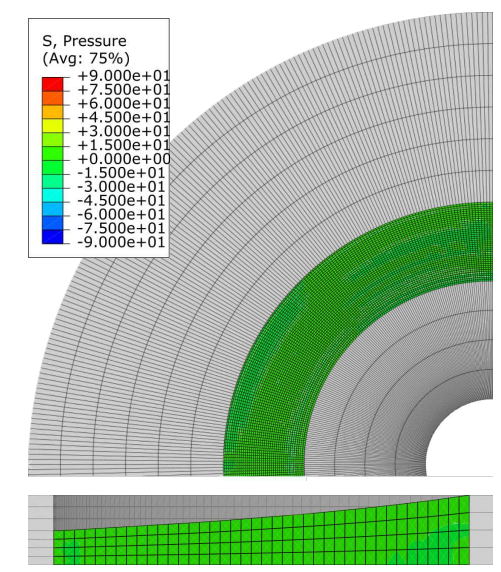

(c) Hydrostatic pressure

Figure 14: Finite element analysis results for the pure shear disc specimen

illustrated in figure 15. In this case, the section in both useful zones is defined by

$$
S(r)=\alpha(r) \cdot r \cdot e_{0}
$$

where $e_{0}$ is the initial thickness and $\alpha(r)$ the parameter to be determined. For instance, in the case of a full disc, the parameter $\alpha$ would be radially constant and equal to $\pi$ for each useful zone. To obtain a homogeneous shear stress field, 
this angle $\alpha$ must evolve along the radius. To this end, in both useful zones, the $\alpha(r)$ parameter has to evolve as a function of $1 / r^{2}$, such that

$$
\begin{aligned}
\forall r, \quad \tau(r)=\frac{C / 2}{\alpha(r) \cdot r^{2} \cdot e_{0}}=c s t & \Rightarrow & \alpha(r) \cdot r^{2}=c s t=b \\
& \Rightarrow & \alpha(r)=\frac{b}{r^{2}}
\end{aligned}
$$

with $b$ a constant parameter to be determined from the boundary conditions. At the minimum radius $R_{\min }$, the section formula is close to the full disc settings so the assumption $b=\pi \cdot \beta \cdot R_{\min }^{2}$ can be made, which leads to

$$
\alpha(r)=\frac{\pi \cdot \beta \cdot R_{\min }^{2}}{r^{2}}
$$

with $\beta$ a constant parameter representing the ratio of the amount of material between the complete and the openshaped disc. In the case of the complete disc, $\beta$ is equal to 1.

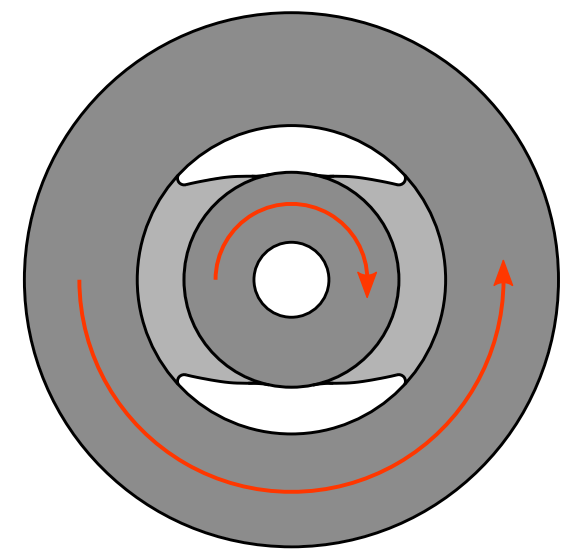

(a) Geometry

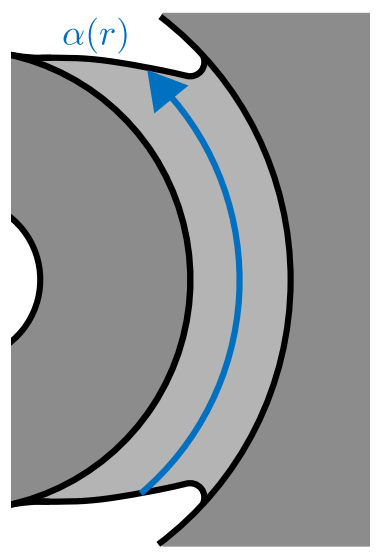

(b) Detailed view

Figure 15: Openshaped shear disc specimen

As before, the $R_{\text {min }}$ parameter defines the clamping area and hence the maximal transmissible torque. The optimal values of both parameters are $R_{\text {min }}=28 \mathrm{~mm}$ and $\beta=0.8$, determined from a series of finite element simulations. As shown in figure 15 the geometry has connecting radii between the 
useful zones and respectively the inner and outer clamping areas. As a consequence, the section in these zones is slightly different from equation 11 defined earlier, but stress concentrations are strongly reduced. Those stress concentrations could not only lead to premature crack initiation but also be responsible for localised plasticity in those areas. The dissipation related to this localized plasticity would be higher than at the center of the useful zones. Consequently, this could have a strong impact on the thermal field which would negatively affect the self-heating measurements. Despite the small stress concentrations, the shear stress field, given by the numerical results shown in figure 16, is prac-

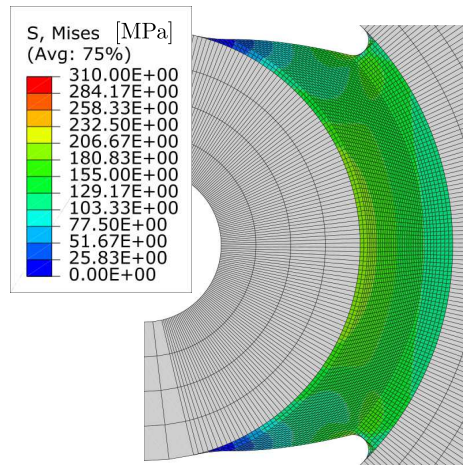

(a) von Mises stress

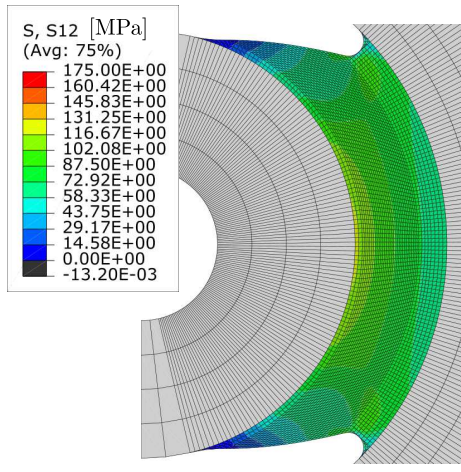

(b) Shear stress

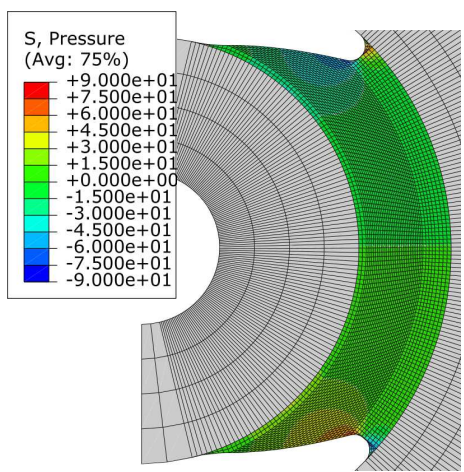

(c) Hydrostatic pressure

Figure 16: Finite element analysis results for the openshaped disc specimen 
tically homogeneous at the center of the useful zone. This new second geometry seems to meet all the requirements.

\subsection{Summary}

Two new specimens were designed for the characterization of fatigue properties under shear conditions from self-heating measurements under cyclic loading. The objective for both geometries was to obtain a homogeneous shear stress field. The first geometry was a disc with a radially variable thickness and the numerical results are very close to the ideal configuration. For the second geometry, two shaped slots were cut in the disc. The stress field is slightly less

homogeneous but the required torque is reduced by $20 \%$ compared with the first geometry. Self-heating measurements were performed on these specimens, as described in the next section.

\section{Material}

The selected material is a hot-rolled High Strength Low Alloyed (HSLA 320) steel grade with a thickness of $2 \mathrm{~mm}$ produced by ArcelorMittal. HSLA steels have low carbon content (i.e., $0.05-0.25 \%$ ) in order to enhance formability and weldability. These steels are particularly suitable for structural components in the automotive industry, such as suspension systems, chassis and reinforcement parts. The chemical composition of the investigated material is provided in table 1. This steel has a ferritic microstructure, with possibly a small fraction of pearlite, hardened by a combination of precipitation strengthening and grain refinement. The grain size is fine and homogeneous (i.e., the mean grain size is about $5 \mu \mathrm{m}$ ), illustrated in figure 17 . The mechanical properties are provided in table 2 in the longitudinal, at $45^{\circ}$ and in the transverse direction and the corresponding monotonic tensile curves are shown in figure 18 . The presence of a yield plateau up to strain value of $2 \%$ is observed in all directions and it can be assumed that the material is isotropic. 


\begin{tabular}{ccccccccccc}
\hline $\mathrm{C}$ & $\mathrm{S}$ & $\mathrm{Mn}$ & $\mathrm{P}$ & $\mathrm{Si}$ & $\mathrm{Cu}$ & $\mathrm{Ni}$ & $\mathrm{Cr}$ & $\mathrm{Al}$ & $\mathrm{Nb}$ & $\mathrm{Fe}$ \\
\hline 0.0576 & 0.006 & 0.330 & 0.008 & 0.008 & 0.021 & 0.019 & 0.036 & 0.045 & 0.0156 & Balance \\
\hline
\end{tabular}

Table 1: Chemical composition of the HSLA320 steel [mass\%]

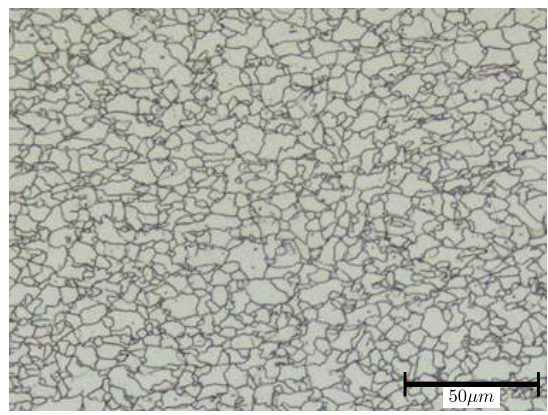

Figure 17: Microstructure of the HSLA320 steel (transverse direction)

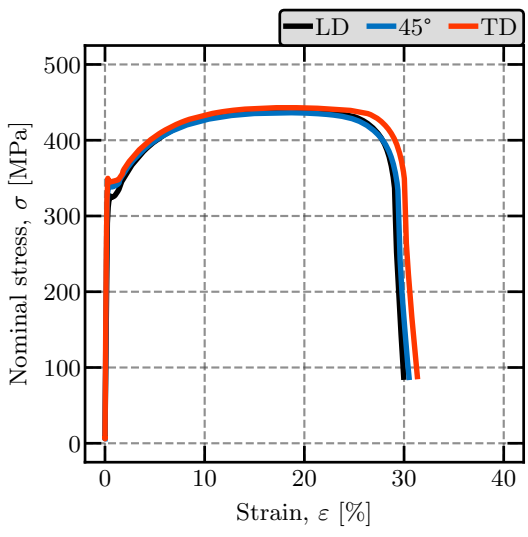

Figure 18: Stress-Strain curve of the HSLA320 steel

\begin{tabular}{cccccc}
\hline Direction & YS [MPa] & UTS [MPa] & TEL [\%] & $\Sigma_{\infty,-1}$ & $\Sigma_{\infty, 0.1}$ \\
\hline LD & 324 & 438 & 29.9 & - & - \\
$45^{\circ}$ & 338 & 436 & 30.5 & - & - \\
TD & 345 & 443 & 31.3 & 210 & 365 \\
\hline
\end{tabular}

Table 2: Mechanical properties of the HSLA320 steel (2mm thickness) with YS the tensile yield strength at $0.2 \%$ of plastic strain, UTS the ultimate tensile strength and TEL the total elongation at fracture given in the longitudinal (LD), at $45^{\circ}$ and in the transverse direction (TD). $\Sigma_{\infty,-1}$ and $\Sigma_{\infty, 0.1}$ the fatigue limits of the material for the load ratios $R=-1$ and $R=0.1$ respectively (in TD only)

\section{Experimental procedure}

\subsection{Test setup}

The testing device was designed to be used on an axial/torsion hydraulic machine, such as an MTS $250 \mathrm{kN} / 2200 \mathrm{Nm}$. It is made of two parts, illustrated in figure 19. The first part is composed of a central shaft allowing the torque 
transmission from the machine to the disc sample. The lower end is linked to the lower clamp of the machine, which is mobile. The sample is positioned at the other end of the central shaft due to a short hub and a shoulder. It is held by a spacer and a clamp nut. The torque is transmitted by adhesion, avoiding any thermal disturbance which may be caused by transmission by obstacles, such as with a grooved or cog shaft. Particular attention should be paid to the clamping force to prevent any sliding or slipping effect. The second part is composed of a bell linking the outer part of the sample to the higher clamp of the machine, which is fixed. To ensure that a pure shear condition is applied in the material, the axial force is kept at zero once the sample is installed.

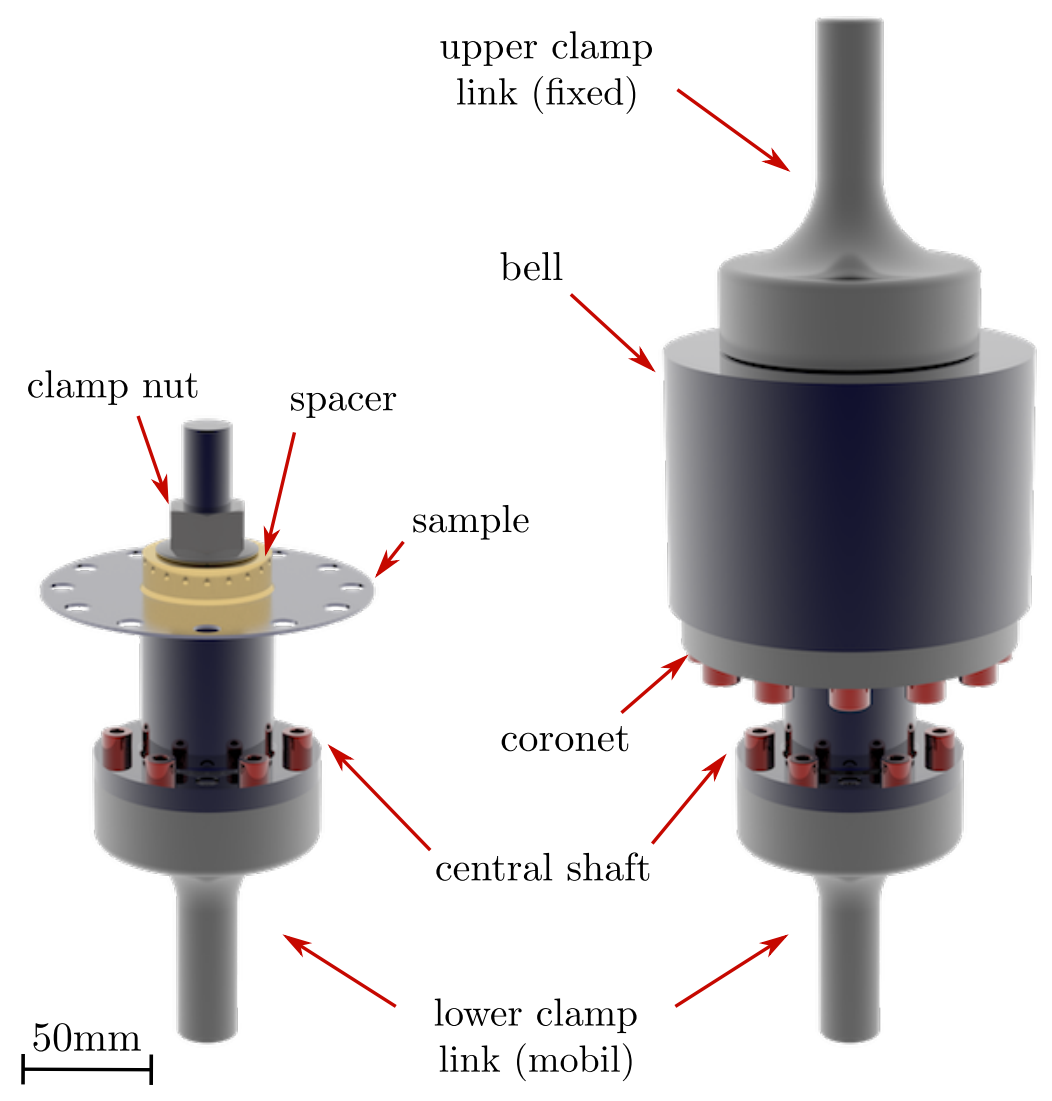

Figure 19: Testing device 


\subsection{Deformation field}

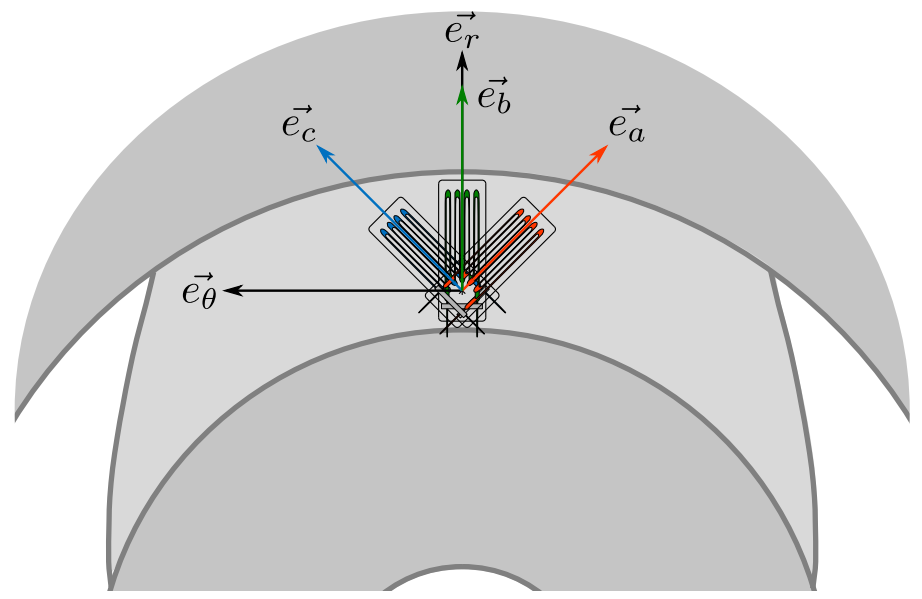

Figure 20: Rosettes strain gauges positioning

In order to verify if the stress field complies with a pure shear stress field, the strain field was analyzed. Rosettes were placed on the useful zones on both new geometries, shown in figure 20 for the openshaped specimen. Rosettes have three strain gauges allowing to measure the strain along three directions and to analyze the strain state. The strains must be symmetrical between the gauges $a$ and $c$ and zero from the gauge $b$. The two principal strains, named $\varepsilon_{I}$ and $\varepsilon_{I I}$, have also to be symmetrical. The theoretical induced shear stress $\tau_{\text {theo }}$ in the useful zone can be determined using the Hooke's law from these principal strains by

$$
\underline{\underline{\sigma_{d}}}=2 \mu \underline{\underline{\varepsilon}}+\lambda \text { Trace }(\underline{\underline{\varepsilon}}) \underline{\underline{I}}
$$

with $\underline{\underline{\sigma_{d}}}$ the principal stress tensor, defined by

$$
\underline{\underline{\sigma_{d}}}=\left(\begin{array}{ccc}
\tau_{\text {theo }} & 0 & 0 \\
0 & -\tau_{\text {theo }} & 0 \\
0 & 0 & 0
\end{array}\right)_{\left(\overrightarrow{e_{1}}, \overrightarrow{e_{2}}, \overrightarrow{e_{z}}\right)}
$$

which gives

$$
\tau_{\text {theo }}=2 \mu \varepsilon_{I} \quad \text { or } \quad-\tau_{\text {theo }}=2 \mu \varepsilon_{I I}
$$


with $\mu=80 \mathrm{GPa}$ the shear modulus. For both geometries, the experimental values along the two principals strains, respectively named $\tau_{\exp 1}$ and $\tau_{\exp 2}$, have to tend to the theoretical one $\tau_{\text {theo }}$.

\subsection{Measurements}

The self-heating protocol under shear loading condition is the same as for a tension/compression loading [9, 32]. A succession of loading blocks with a constant stress amplitude is applied to the sample. One of the main objective of this study is to use a 0D thermal approach for the self-heating measurements, i.e. thermocouple measurements are sufficient. The entire temperature field of the useful zone has to be measured to validate the use of such an approach. The mean value of the stabilized temperature must conform with measurements from the thermocouples. For each test, self-heating measurements were made by thermocouples and compared with an infrared (IR) camera. The accuracy of the type $\mathrm{K}$ thermocouples used is about $0.1 \mathrm{~K}$ and its response time is in the order of one second. The IR camera used is a FLIR SC7600 with an accuracy of $0.01 \mathrm{~K}$. Three thermocouples were positioned, one on the useful zone and the two others on the coronet and the central shaft respectively. For the IR measurements, the

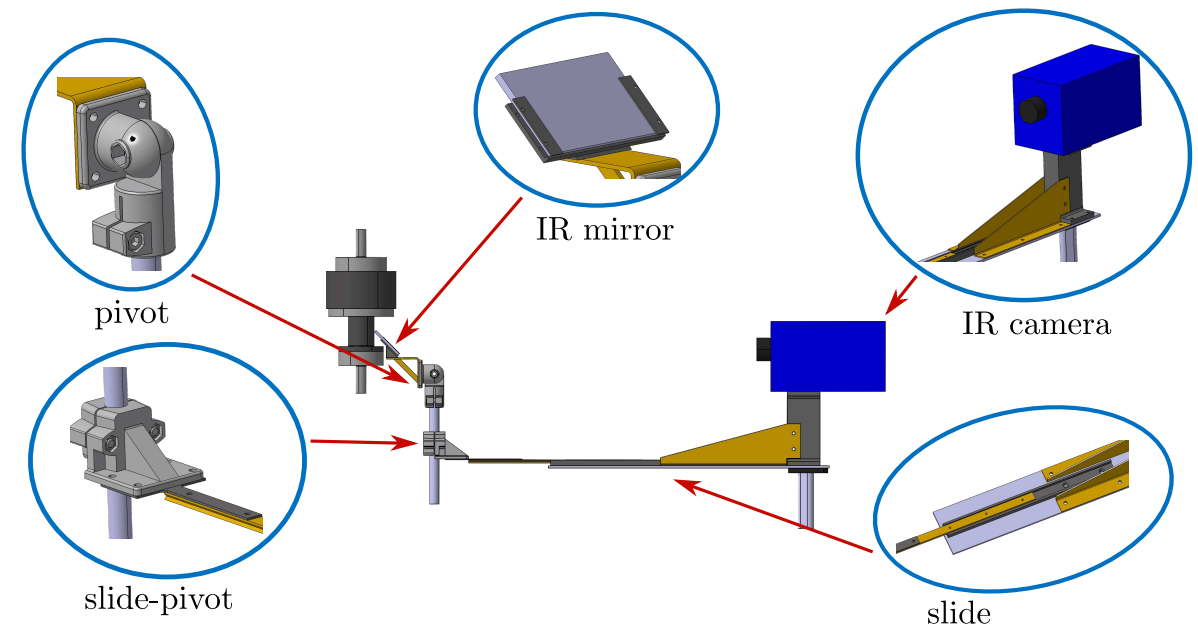

Figure 21: Infrared mirror positioning device 
useful zone is not directly observable. To overcome this problem, an IR mirror is used and a positioning device was developed, shown in figures 21 and 22 . This allows for observation of the thermal field during cyclic loading. To compare the IR measurements with the thermocouples, the average temperature has been computed in the same zones where thermocouples were placed, shown in figure 22 (openshaped specimen) where the blue and black rectangles correspond to the zones 1 and 2, and the red rectangle corresponds to the useful zone. The thermal field seems to be homogeneous in the useful zone which is the best way to use a 0D thermal approach.

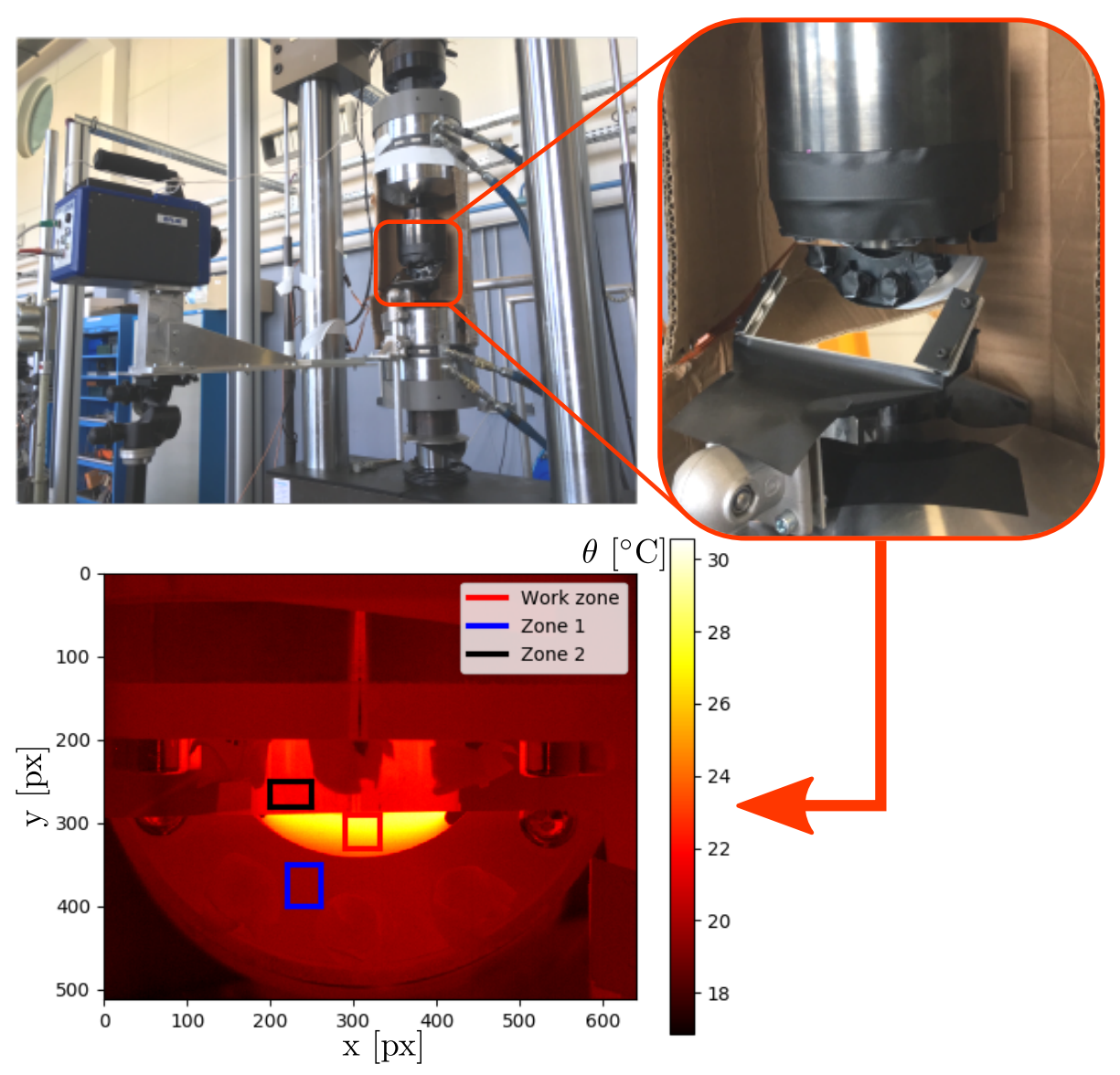

Figure 22: Infrared image acquisition with the openshaped specimen 


\section{Experimental results}

For the strain analysis, a ramp loading, shown in figure 23, was applied on both geometries. The strain data from the rosettes for both geometries are shown in figures 24 and 25 . The strains along both gauges $b$ are almost zero even though it is slightly greater for the openshaped disc. This is probably because the stress field is not completely homogeneous in all of the useful zone for this geometry. The strains along both gauges $a$ and $c$ are symmetrical as well as for the principal strains. Consequently, the strain field is practically a homogeneous shear strain. In addition, the experimental values of the shear stress along both principal directions are identical to the theoretical values, shown in figure 26, as predicted by the numerical investigations. Moreover, this figure demonstrates that for a quasi-static loading of $400 \mathrm{Nm}$, the induced shear stress in the openshaped specimen is $50 \mathrm{MPa}$ whereas in the pure shear disc specimen it is 40MP. Consequently, to obtain the same shear stress state in both geometries, the required torque is reduced by $20 \%$.

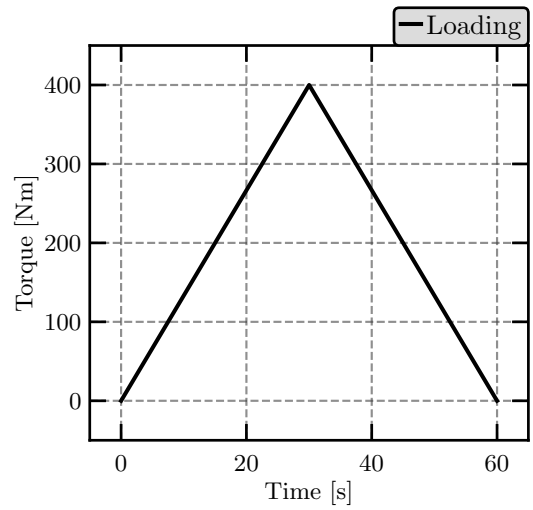

Figure 23: Loading applied for the strain field analysis on both geometries

For both geometries, each loading block applied during self-heating measurements is composed of 1500 cycles at a frequency of $10 \mathrm{~Hz}$. Figure 27 presents the self-heating measurements for the openshaped disc specimen from the thermocouples and the IR camera. These are in accordance with the classical self- 
heating measurements under uniaxial loading.

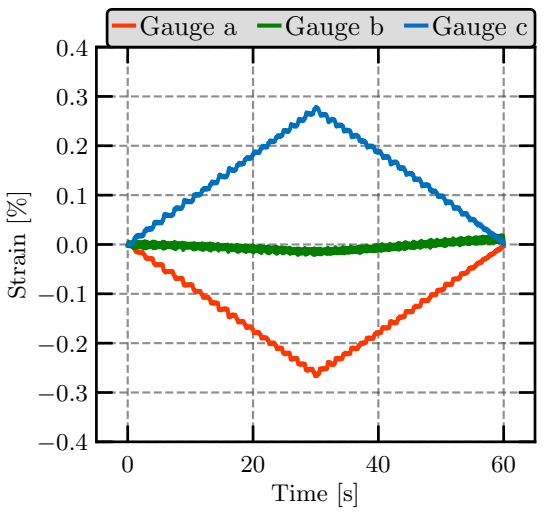

(a) principal strain

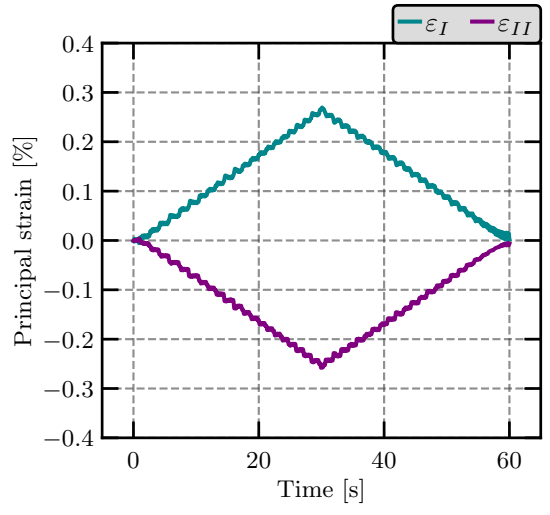

(b) strain gauges

Figure 24: Pure shear strain validation from measured strain gauges placed on the pure shear disc specimen

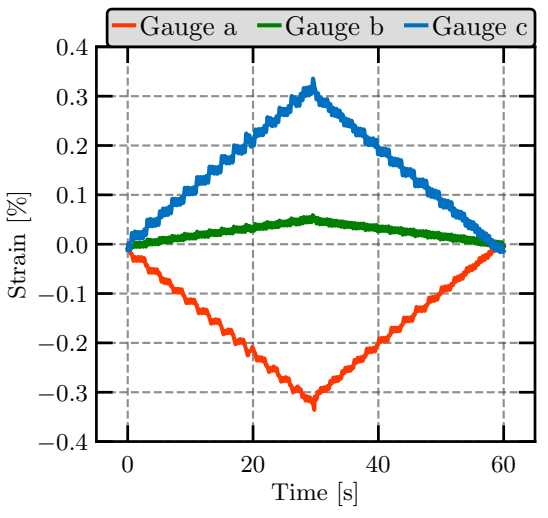

(a) principal strain

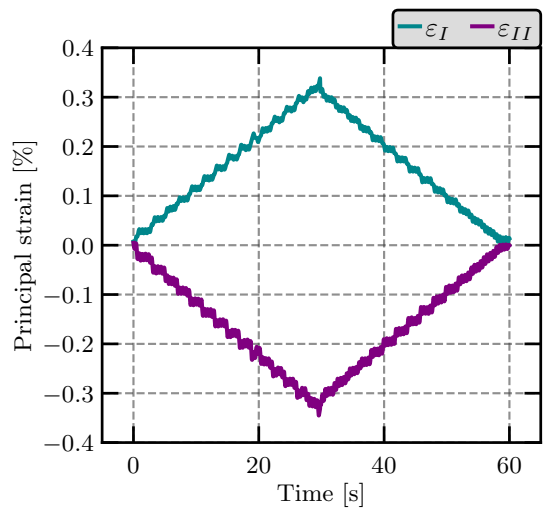

(b) strain gauges

Figure 25: Pure shear strain validation from measured strain gauges placed on the openshaped disc specimen

It has been shown that the self-heating phenomenon in steels is due to the dissipation of microplasticity. Under cyclic loading, two microplasticity mech- 


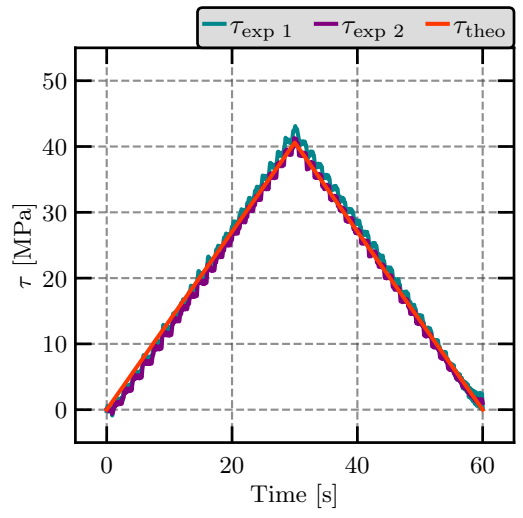

(a) Pure shear disc

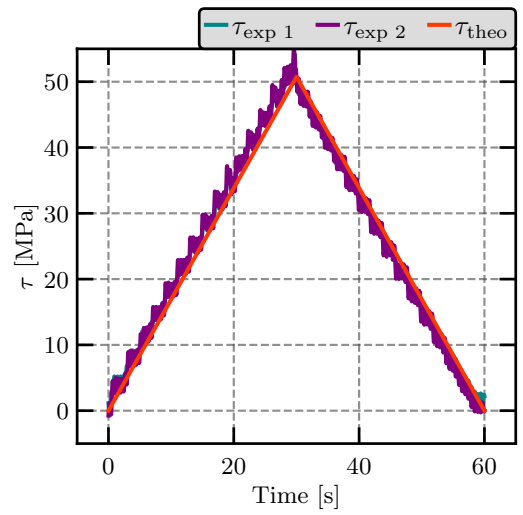

(b) Openshaped disc

Figure 26: Comparison between the experimental and the theoretical shear stress for both geometries

anisms may take place depending on the stress amplitude [33]: a diffuse microplasticity all over the microstructure and a localized microplasticity inside grains. The latter is responsible for failure by fatigue. Two self-heating regimes can be observed on a self-heating curves [32, corresponding to the dissipation of both microplasticity mechanisms. The mean fatigue limit is assessed at the start of the secondary dissipative regime 24, i.e. the first dissipation point which no longer corresponds entirely to the primary regime. This limit corresponds to the mean fatigue limit at 2 million cycles 32 . Using a $0 \mathrm{D}$ thermal approach, the self-heating curves are shown in figures 28 and 29 from both measurement sources for both geometries. Results are plotted as a function of the stress amplitude expressed as von Mises equivalent stress $\Sigma_{0}^{\mathrm{VM}}$. The first important result is that the shape of the curves is the same as a classical self-heating curve with two regimes apparent in a logarithmic scale [9]. Secondly, the comparison between the results from the IR camera and the thermocouples gives almost the same results so the use of thermocouples is sufficient. Consequently, the 0D thermal approach can be adopted. In addition, both geometries have been tested twice, demonstrating that those tests are repeatable, as illustrated in 
figure 30 .

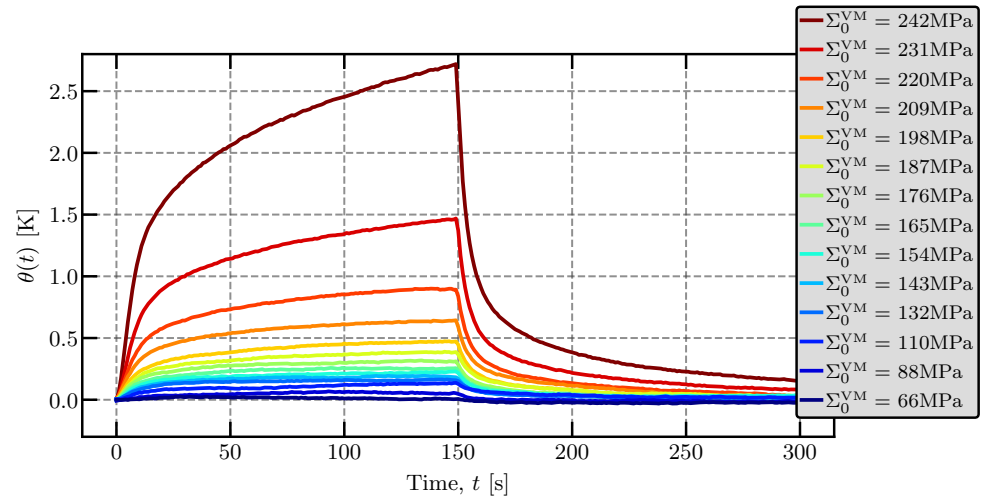

(a) IR camera

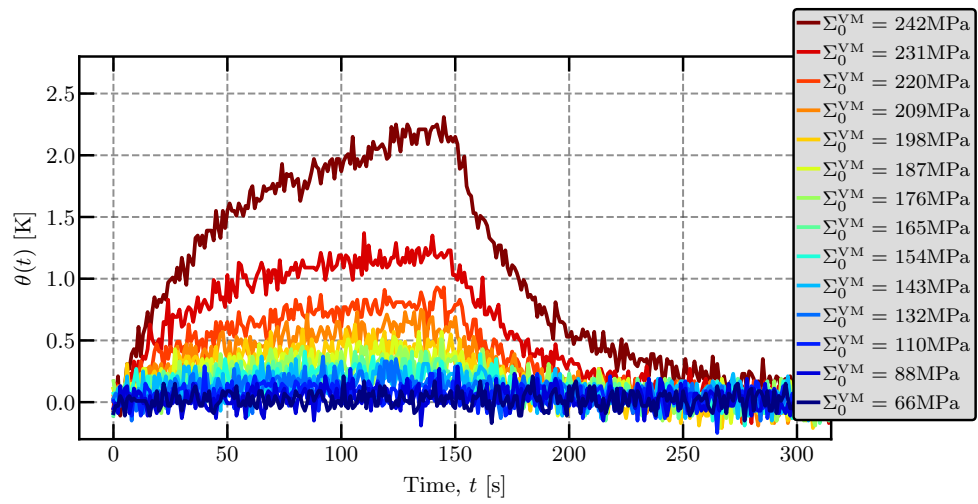

(b) Thermocouples

Figure 27: Example of self-heating measurements from IR camera and thermocouples for the openshaped specimen - Each loading bloc are composed of 1500 cycles at a frequency of $10 \mathrm{~Hz}$

From self-heating measurements, the identified mean shear fatigue limits are assessed at $230 \mathrm{MPa}$ for the pure shear disc specimen and $210 \mathrm{MPa}$ for the openshaped specimen, in sense of the von Mises stress, given in table 3 . The estimated fatigue limit of the second geometry is slightly lower than the first. This might be explained by the stress concentration areas in the openshaped sample. Those stress concentrations may lead to a premature failure by fatigue as compared to the pure shear disc specimen. 


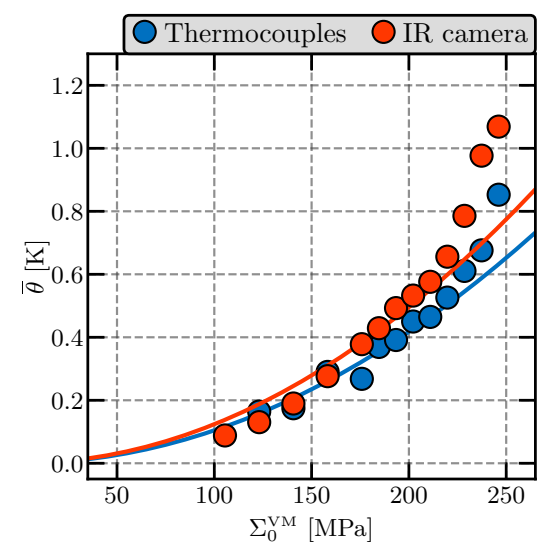

(a) Linear scale

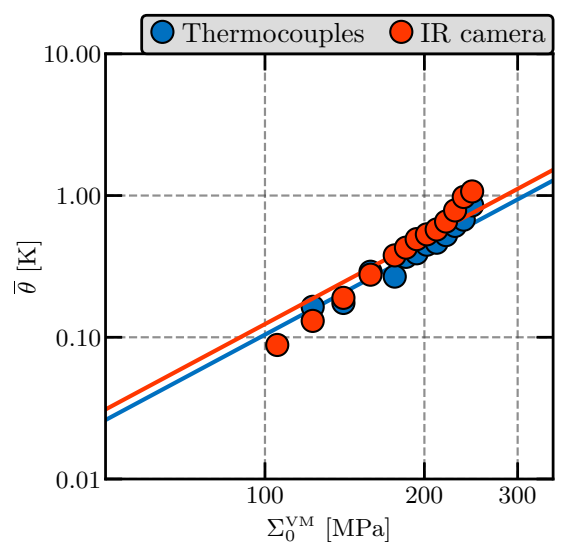

(b) Logarithm scale

Figure 28: Self-heating curves from thermocouples and infrared camera for the pure shear disc specimen (solid lines $=$ primary regime evolution)

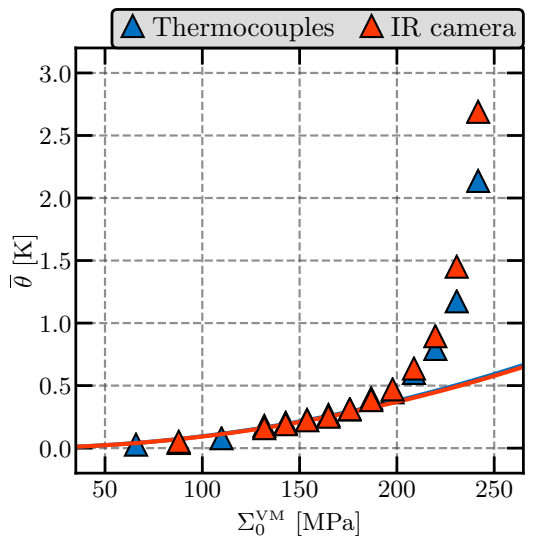

(a) Linear scale

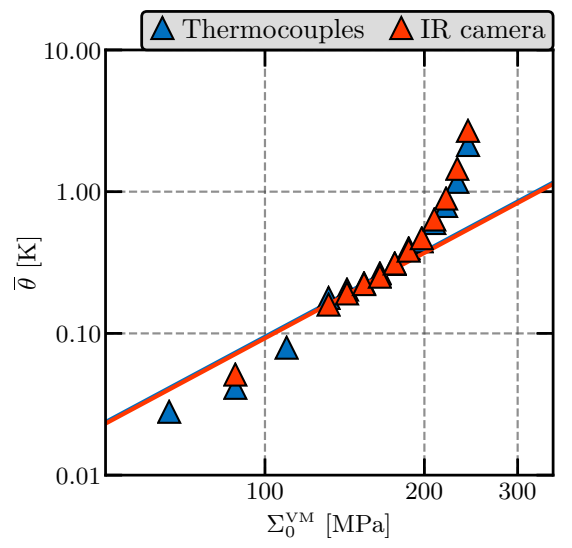

(b) Logarithm scale

Figure 29: Self-heating curves from thermocouples and infrared camera for the openshaped disc specimen (solid lines $=$ primary regime evolution) 


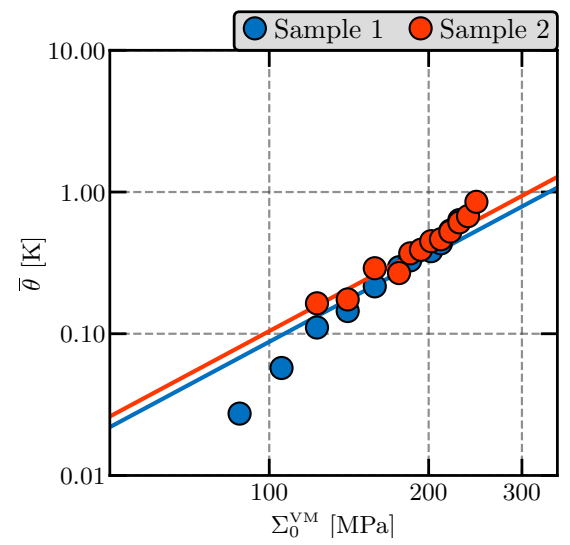

(a) Pure shear disc

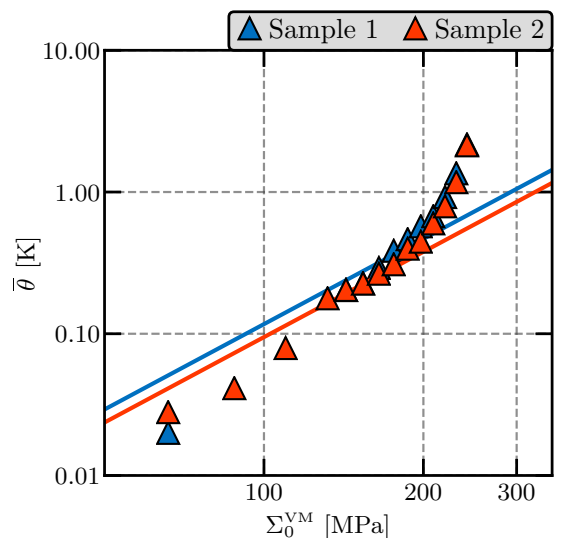

(b) Openshaped disc

Figure 30: Repeatability tests for both geometries measured by means of thermocouples (logarithm scale, solid lines $=$ primary regime evolution)

\begin{tabular}{ccc}
\hline Specimen & $\bar{\Sigma}_{\infty}^{\mathrm{VM}}[\mathrm{MPa}]$ & $\tau_{\infty}[\mathrm{MPa}]$ \\
\hline Pure shear disc & 230 & 133 \\
Openshaped & 210 & 121 \\
\hline
\end{tabular}

Table 3: Mean shear fatigue limits identified from the self-heating measurements

These results can be plotted in a Crossland diagram, shown in figure 31 This criterion is defined by

$$
\frac{J_{2}\left(\underline{\underline{\underline{\Sigma_{0}}}}\right)+\alpha_{c} I_{1 m}(\underline{\underline{\Sigma}}(t))}{\beta_{c}} \leq 1
$$

where $J_{2}\left(\underline{\underline{\Sigma_{0}}}\right)$ is the second invariant of the stress amplitude deviator tensor, defined by

$$
\begin{aligned}
J_{2}\left(\underline{\underline{\Sigma_{0}}}\right) & =\max _{t}\left\{J_{2}\left(\underline{\underline{\Sigma}}(t)-\underline{\underline{\Sigma_{\text {moy }}}}\right)\right\} \\
& =\max _{t}\left\{\sqrt{\frac{3}{2}\left(\underline{\underline{\Sigma}}(t)-\underline{\underline{\Sigma_{\text {moy }}}}\right)^{\mathrm{d}}:\left(\underline{\underline{\Sigma}}(t)-\underline{\underline{\Sigma_{\text {moy }}}}\right)^{\mathrm{d}}}\right\}
\end{aligned}
$$


with $\left(\underline{\underline{\Sigma}}(t)-\underline{\underline{\Sigma_{\text {moy }}}}\right)^{\mathrm{d}}$ the deviatoric tensor of the stress $\left(\underline{\underline{\Sigma}}(t)-\underline{\underline{\Sigma_{\text {moy }}}}\right)$, and $I_{1 m}(\underline{\underline{\Sigma}}(t))$ the maximum value of the first invariant of the stress tensor, given by

$$
I_{1 m}(\underline{\underline{\Sigma}}(t))=\max _{t}\{\operatorname{Trace}(\underline{\underline{\Sigma}}(t))\}
$$

and $\alpha_{c}$ and $\beta_{c}$ two parameters to be determined, as

$$
\alpha_{c}=\frac{\tau_{\infty,-1}}{\Sigma_{\infty,-1}}-\frac{1}{\sqrt{3}} \quad \text { and } \quad \beta_{c}=\tau_{\infty,-1}
$$

with $\tau_{\infty,-1}$ and $\Sigma_{\infty,-1}$ respectively the fatigue limit for a load ratio $R=-1$ under a pure shear and a tension/compression loading. This criterion is illustrated by a straight line with $\alpha_{c}$ and $\beta_{c}$ are respectively the slope and the intercept. This line delimits the safe and the failure zone. In the case of flat steel, two loading ratios are considered to plot the Crossland line, usually $R=0.1$ and $R=-1$. Using two new geometries described here, the fatigue limit under pure shear loading can be determined. Figure 31 provides a comparison between the

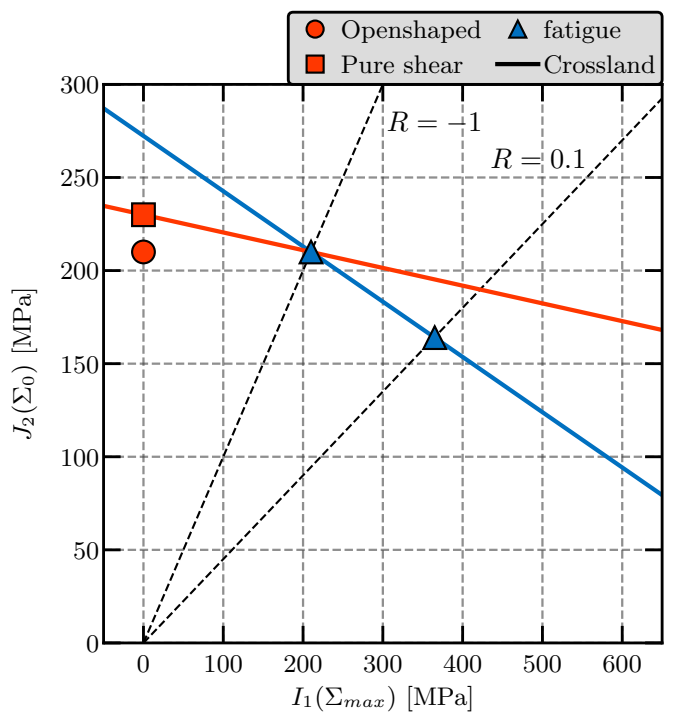

Figure 31: Comparison of the Crossland criterion between the regular strategy, i.e. considering two load ratio $R=-1$ and $R=0.1$, and the original strategy, i.e. considering one load ratio set at -1 and the pure shear fatigue limit 
regular strategy, i.e. considering two loading ratios (blue line and points), and the original strategy, i.e. considering one load ratio set at $R=-1$ and the pure shear fatigue limit (red line and points). This figure clearly highlights the error made by the Crossland criterion considering only two points of fatigue. The criterion determined by the regular strategy (blue line) overestimates the fatigue limit for multiaxial loading close to a pure shear state, whereas with the original strategy (red line) it overestimates the fatigue limit for a multiaxial loading with a large value of the first invariant $I_{1}\left(\Sigma_{\max }\right)$.

\section{Discussion}

The first proposed geometry, the pure shear disc specimen, presents an ideal shear strain field in the working area. The purpose of the openshaped specimen was to reduce the required torque by constraining the strain field. Only the center of the working zone presents a pure shear condition. Despite the fact that the shear strain field in the working zone of the openshaped specimen is not homogeneous, no substantial difference was found between both geometries. The self-heating measurements from the openshaped specimen are slightly higher than from the pure shear disc specimen, which results in a slight underestimate the mean fatigue limit. This could be explained by the appearance of stress concentrations induced by the connecting radii. Nevertheless, the mean fatigue limits under cyclic shear loading assessed by self-heating measurements for both geometries are in good agreement.

Given that no classical fatigue test can be carried out under cyclic shear conditions on thin steel sheets without modifying the initial state of the material, these findings cannot be compared to a regular fatigue campaign. So, the conclusions must be treated with caution. However, it would be interesting to machine these two new geometries from bulk material from which regular cylindrical specimens could also be obtained. In this way, the results from the methodology presented in this paper could be compared to the results from a classic fatigue campaign under torsional loading. 
The figure 31 highlights that the restricted use of two mean fatigue limits seems to be insufficient to characterize material under multiaxial cyclic loading. This underlines how important the calibration of multiaxial fatigue criteria is. With the two new specimens proposed in this paper, assessment of the Crossland criterion can be made with higher accuracy under multiaxial loading close to a pure shear condition for thin steel sheets.

The new test specimens may have limitations regarding the maximum transmissible torque. For steel grades with higher strength than the material in this paper, the required torque could be higher than the maximum transmissible torque by the testing setup.

\section{Conclusions}

In the case of thin steel sheets, the determination of fatigue limit under pure shear loading is difficult. To overcome this limitation, a new test under pure shear cyclic loading for flat steel samples was designed. First, a bibliographic review of existing shearing tests was provided as well as finite element analysis for each configuration. The stress field in the useful zone of every sample has

been analyzed and compared to the requirements. This has shown that none of the existing tests is suitable and the need to develop a new shear test.

Two new geometries were proposed in order to assess the fatigue limit of thin sheet material under a pure shear cyclic loading. Thermal measurements from thermocouples and an infrared camera were in good agreement and validated the 0D thermal approach to obtain self-heating curves. The strain field was validated by means of strain gauges placed on both specimens, showing pure shear loading conditions. Consequently, the fatigue limit under a pure shear cyclic loading can be determined with this new shear test. Further, multiaxial fatigue criteria, such as the Crossland criterion, can be determined to assess the fatigue life of structures under multiaxial loadings.

The development of the test was very difficult and had a lot of challenges such as the torque transmission, the set-up alignment and the thermal acquisition. 
Some improvements would have to be proposed in order to make this testing device more practical and usable and to perform some tests with other materials requiring a higher torque.

\section{Acknowledgements}

This work has been performed as part of the durability team at the Institut de Recherche Dupuy de Lôme (IRDL, UMR CNRS 6027, France) and supported by ArcelorMittal Global R\&D and the national association of research and technology of France (ANRT).

[1] ASTM, 2005. Test method for shear testing of thin aluminum alloy products. ASTM Int.

[2] Bouvier, S., Haddadi, H., Levée, P., Teodosiu, C., 2006. Simple shear tests: Experimental techniques and characterization of the plastic anisotropy of rolled sheets at large strains. Journal of Materials Processing Technology $172(1), 96-103$.

[3] Brosius, A., Yin, Q., Güner, A., Tekkaya, A. E., 2011. A new shear test for sheet metal characterization. Steel Research International 82, 323-328.

[4] Charkaluk, E., Constantinescu, A., 2009. Dissipative aspects in high cycle fatigue. Mechanics of Materials 41 (5), 483-494.

[5] Chrysochoos, A., Louche, H., 2000. An infrared image processing to analyse the calorific effects accompanying strain localisation. International Journal of Engineering Science 38 (16), 1759-1788.

[6] Crossland, B., 1956. Effect of large hydrostatic pressures on the torsional fatigue strength of an alloy steel. International conference on fatigue of metals $6(3), 12$.

[7] Doudard, C., 2004. Dtermination rapide des proprits en fatigue grand nombre de cycles partir d'essais d'chauffement. Ph.D. thesis, ENS Cachan. 
[8] Doudard, C., Calloch, S., 2009. Influence of hardening type on self-heating of metallic materials under cyclic loadings at low amplitude. European Journal of Mechanics-A/Solids 28 (2), 233-240.

[9] Doudard, C., Calloch, S., Cugy, P., Galtier, A., Hild, F., 2005. A probabilistic two-scale model for high-cycle fatigue life predictions. Fatigue and Fracture of Engineering Materials and Structures 28 (3), 279-288.

[10] Doudard, C., Calloch, S., Hild, F., Roux, S., 2010. Identification of heat source fields from infrared thermography: Determination of self-heatingin a dual-phase steel by using a dog bone sample. Mechanics of Materials 42 (1), $55-62$.

[11] Ezanno, A., Doudard, C., Calloch, S., Heuzé, J.-L., 2013. A new approach to characterizing and modeling the high cycle fatigue properties of cast materials based on self-heating measurements under cyclic loadings. International Journal of Fatigue 47, 232-243.

[12] Florin, P., 2015. Caractérisation rapide des propriétés à la fatigue à grand nombre de cycle des assemblages métalliques soudés de type automobile: vers une nouvelle approche basée sur des mesures thermométriques. Ph.D. thesis, Universit de Bretagne Occidentale.

[13] Galtier, A., 1993. Contribution à l'étude de l'endommagement des aciers sous sollicitations uni ou multi-axiales. Ph.D. thesis, Paris, ENSAM.

[14] Galtier, A., Bouaziz, O., Lambert, A., 2002. Influence de la microstructure des aciers sur leur propriétés mécaniques. Mécanique \& industries 3 (5), $457-462$.

[15] Galtier, A., Weber, B., 2005. Fatigue tests on thin sheet materials. In: Fatigue Design. pp. 1-9.

[16] Gasperini, M., Pinna, C., Swiatnicki, W., 1996. Microstructure evolution and strain localization during shear deformation of an aluminium alloy. Acta materialia 44 (10), 4195-4208. 
[17] Genevois, P., Teodosiu, C., Moussy, F., 1990. The test of simple shear: experimental techniques and application to the identification of constitutive laws for metal sheet. Sheet Metals in Forming Processes, 53-61.

[18] Graux, N., 2017. Caractérisation et modélisation des propriétés à la fatigue à grand nombre de cycles des aciers cémentés à partir d'essais d'autoéchauffement sous sollicitations cycliques. Ph.D. thesis, Universit de Bretagne Occidentale.

[19] Klepaczko, J. R., Nguyen, H. V., Nowacki, W. K., 1999. Quasi-static and dynamic shearing of sheet metals. European Journal of Mechanics-A/Solids 18 (2), 271-289.

[20] La Rosa, G., Risitano, A., 2000. Thermographic methodology for rapid determination of the fatigue limit of materials and mechanical components. International journal of fatigue $22(1), 65-73$.

[21] Lemaitre, J., Doghri, I., 1994. Damage 90: a post processor for crack initiation. Computer methods in applied mechanics and engineering 115 (3-4), 197-232.

[22] Lemaitre, J., Sermage, J., Desmorat, R., 1999. A two scale damage concept applied to fatigue. International Journal of fracture 97 (1-4), 67.

[23] Liu, Y., 1990. Influence of shear strain, as a pre-deformation, on the subsequent mechanical properties of A-K steel. Journal of materials processing technology 21, 51-63.

[24] Louge, J., 2019. Apports des mesures d'auto-échauffement pour l'étude de la fatigue des aciers: effets d'histoire et cisaillement pur. Thèse de doctorat, ENSTA Bretagne.

[25] Marciniak, Z., 1961. Influence of the sign change of the load on the strain hardening curve of a copper test subject to torsion. Archiwum Mechaniki Stosowanj 13, 743-751. 
[26] Mareau, C., 2007. Modélisation micromécanique de l'échauffement et de la microplasticité des aciers sous sollicitations cycliques. Ph.D. thesis, Arts et Métiers ParisTech.

[27] Merklein, M., Biasutti, M., 2011. Forward and reverse simple shear test experiments for material modeling in forming simulations. International conference on technology of plasticity, Achen, 702-707.

[28] Miyauchi, K., 1984. A proposal for a planar simple shear test in sheet metals. Sci. Papers RIKEN 81, 27-42.

[29] Mohr, D., Henn, S., 2007. Calibration of stress-triaxiality dependent crack formation criteria: a new hybrid experimental-numerical method. Experimental Mechanics 47 (6), 805-820.

[30] Mohr, D., Oswald, M., 2008. A new experimental technique for the multiaxial testing of advanced high strength steel sheets. Experimental Mechanics $48(1), 65-77$.

[31] Munier, R., 2012. Etude de la fatigue des aciers laminés à partir de l'autoéchauffement sous sollicitation cyclique : essais, observations, modélisation et influence d'une pré-déformation plastique. Thèse de doctorat, Universit de Bretagne Occidentale.

[32] Munier, R., Doudard, C., Calloch, S., Weber, B., 2014. Determination of high cycle fatigue properties of a wide range of steel sheet grades from self-heating measurements. International Journal of Fatigue 63, 46-61.

[33] Munier, R., Doudard, C., Calloch, S., Weber, B., 2017. Identification of the micro-plasticity mechanisms at the origin of self-heating under cyclic loading with low stress amplitude. International Journal of Fatigue 103, $122-135$.

[34] Peirs, J., Verleysen, P., Degrieck, J., 2012. Novel technique for static and dynamic shear testing of ti6al4v sheet. Experimental mechanics 52 (7), 729-741. 
[35] Rauch, E., 1998. Plastic anisotropy of sheet metals determined by simple shear tests. Materials Science and Engineering: A 241 (1), 179-183.

[36] Rauch, E., 2009. Plastic behavior of metals at large strains: experimental studies involving simple shear. Journal of engineering materials and technology $131(1)$.

[37] Roth, C. C., Mohr, D., 2016. Ductile fracture experiments with locally proportional loading histories. International Journal of Plasticity 79, 328354.

[38] Stromeyer, C., 1914. The determination of fatigue limits under alternating stress conditions. Proc. R. Soc. Lond. A 90 (620), 411-425.

[39] Yin, Q., Soyarslan, C., Güner, A., Brosius, A., Tekkaya, A. E., 2012. A cyclic twin bridge shear test for the identification of kinematic hardening parameters. International Journal of Mechanical Sciences 59 (1), 31-43.

[40] Yin, Q., Soyarslan, C., Isik, K., Tekkaya, A., 2015. A grooved in-plane torsion test for the investigation of shear fracture in sheet materials. International Journal of Solids and Structures 66, 121-132.

[41] Yin, Q., Zillmann, B., Suttner, S., Gerstein, G., Biasutti, M., Tekkaya, A. E., Wagner, M. F.-X., Merklein, M., Schaper, M., Halle, T., et al., 2014. An experimental and numerical investigation of different shear test configurations for sheet metal characterization. International Journal of Solids and Structures 51 (5), 1066-1074. 